\title{
Incidence and causes of severe neonatal hyperbilirubinemia in Canada
}

\author{
Michael Sgro, Douglas Campbell, Vibhuti Shah
}

$\infty$

See related article page 599

\section{ABSTRACT}

Background: Severe hyperbilirubinemia is the most common cause of neonatal readmission to hospital in Canada even though, in the majority of cases, risk factors can be identified before discharge. Severe neonatal hyperbilirubinemia and kernicterus continue to be reported worldwide in otherwise healthy term infants. We conducted this study to estimate the incidence of severe neonatal hyperbilirubinemia in Canada and to determine underlying causes, improved knowledge of which would be valuable to help identify strategies for risk reduction.

Methods: Data on term infants 60 days of age and younger with unconjugated hyperbilirubinemia were collected prospectively through the Canadian Paediatric Surveillance Program from 2002 to 2004 . Infants were included if they had a peak serum total bilirubin level of more than $425 \mu \mathrm{mol} / \mathrm{L}$ or underwent an exchange transfusion. Infants with rhesus isoimmunization or who were born at less than 36 weeks' gestation were excluded.

Results: Of 367 cases reported, 258 were confirmed to be severe neonatal hyperbilirubinemia, for an estimated incidence of 1 in 2480 live births. Causes were identified in 93 cases and included ABO incompatibility $(n=48)$, glucose-6phosphate dehydrogenase deficiency $(n=20)$, other antibody incompatibility $(n=12)$ and hereditary spherocytosis $(n=7)$. The mean peak bilirubin level reported was $471 \mu \mathrm{mol} / \mathrm{L}$ (standard deviation [SD] $76 \mu \mathrm{mol} / \mathrm{L}$, range 156 $841 \mu \mathrm{mol} / \mathrm{L})$. Fifty-seven infants (22.1\%) underwent an exchange transfusion. A total of 185 infants $(71.7 \%)$ were readmitted to hospital, $121\left(6_{5} .4 \%\right)$ of them within 5 days of age.

Interpretation: Severe neonatal hyperbilirubinemia continues to occur frequently in Canada. In the majority of cases, the underlying cause was not identified. The high readmission rate within days after initial discharge indicates a need for a more thorough assessment of newborn infants and consideration of strategies to identify at-risk newborns, such as predischarge measurement of serum bilirubin levels.

$C M A J$ 2006; $175(6): 587-90$
S

evere hyperbilirubinemia continues to be the most common cause of neonatal readmission to hospitals in North America. ${ }^{1-5}$ This pattern continues despite attempts to identify newborns at risk of clinically important hyperbilirubinemia before they are discharged from hospital. ${ }^{6-9}$ Long-term results of severe hyperbilirubinemia, including bilirubin encephalopathy and kernicterus, were thought to be rare since the advent of exchange transfusion, maternal rhesus immunoglobulin prophylaxis and phototherapy. ${ }^{10-12}$ However, cases of kernicterus have been reported recently in healthy near-term and term infants with no evidence of hemolytic disease or other risk factors. ${ }^{13,14} \mathrm{As}$ a result, a sentinel event alert was issued by the US Centers for Disease Control and Prevention to identify cases of kernicterus in healthy term infants. ${ }^{11}$ The resurgence of severe neonatal hyperbilirubinemia and kernicterus (a largely preventable disease) is of grave concern.

Risk factors recognized to be associated with severe hyperbilirubinemia in newborns have included jaundice in the first 24 hours of life, jaundice noted before discharge from hospital, a sibling who had jaundice treated with phototherapy, near-term gestational age of $35-36$ weeks, Asian race and the presence of infant bruising or cephalhematoma. ${ }^{15-17}$ Causes identified by laboratory investigations include rhesus and $\mathrm{ABO}$ incompatibility, as well as glucose-6-phosphate dehydrogenase (G6PD) deficiency. ${ }^{18,19}$

We conducted this study to estimate the incidence of severe hyperbilirubinemia in Canada and to determine the underlying causes, which would be of value in identifying and implementing strategies to prevent morbidity from this condition.

\section{Methods}

The Canadian Paediatric Surveillance Program (CPSP) was used to study severe neonatal hyperbilirubinemia in Canada. This program surveys more than 2400 Canadian pediatricians and pediatric subspecialists to obtain national surveillance and research data on uncommon pediatric diseases and conditions. Pediatricians and pediatric subspecialists were targeted for this study since it would be expected that infants meeting the case definition would be seen by a pediatrician at 
some point in their care. A 2-tiered reporting process was used to collect the data. A monthly check-off form was mailed to participants asking them to return the form to the CPSP regardless of whether or not they identified a new case. A detailed questionnaire, developed by the research team, was then sent out to those who reported cases in order to gather clinical data and information related to the cause of the hyperbilirubinemia and analyzed by the investigators. Quarterly reminders were mailed to participants who had not responded each month. The CPSP assured the confidentiality of all information provided, since only date of birth and sex were requested. The study case definition, protocol and questionnaire were reviewed and approved by the CPSP steering committee panel of experts and by the research ethics boards of 3 hospitals in Toronto (St. Michael's Hospital, Mount Sinai Hospital and The Hospital for Sick Children).

Infants aged 6o days and less with unconjugated hyperbilirubinemia were included for assessment if they had a peak serum total bilirubin level of more than $425 \mu \mathrm{mol} / \mathrm{L}$ or had undergone a neonatal exchange transfusion, or both.

A bilirubin level of more than $425 \mu \mathrm{mol} / \mathrm{L}$ was chosen to define severe hyperbilirubinemia since an infant with this degree of jaundice is thought to be at high risk of kernicterus. ${ }^{6}$ Furthermore, the Canadian Paediatric Society recommends considering an exchange transfusion at this level in healthy term infants without risk factors. ${ }^{20}$

Infants who had rhesus iso-immunization were excluded since antenatal and postnatal strategies already exist to prevent the occurrence of severe neonatal hyperbilirubinemia from this cause. Infants who were born at less than 36 weeks' gestational age were also excluded.

Data were summarized using descriptive statistics. Continuous variables were analyzed using the independent Student's $t$-test. Fisher's exact test was used to test associations between other antibody incompatibility and discharge groups. A $\chi^{2}$ test was used to test associations between all other categorical variables.

Table 1: Baseline demographic characteristics

\begin{tabular}{lc}
\hline Characteristic & $\begin{array}{c}\text { No. }(\%) \text { of infants* } \\
n=258\end{array}$ \\
\hline Gestational age, wk, mean (SD) & $38.5(1.4)$ \\
\hline Sex, male & $162(62.8)$ \\
\hline Birth weight, g, mean (SD) & $3360(489)$ \\
\hline Age at presentation, h, mean (SD) & $111.6(66)$ \\
\hline Breast-feeding & $210(81.4)$ \\
Readmission & $185(71.7)$ \\
\hline Peak total bilirubin level, $\mu$ mol/L, & $471(76)$ \\
mean (SD) & $28(10.9)$ \\
\hline Weight loss $\dagger$ of $10 \%-15 \%$ & $11(4.3)$ \\
\hline Weight loss $\dagger$ of $>15 \%$ & \\
\hline
\end{tabular}

Note: $\mathrm{SD}=$ standard deviation.

*Unless stated otherwise.

†Calculated as birth weight - readmission weight $\times 100$. birth weight

\section{Results}

From July 2002 to June 2004,367 cases of severe neonatal hyperbilirubinemia were reported. Of these, 258 met the inclusion criteria for this study, for an estimated incidence of $\mathrm{I}$ in 2480 live births. There were 42 duplicate reports, 48 that did not fulfill the case definition and ig $(6.9 \%$ of cases that met the definition) that had incomplete data. The mean peak bilirubin level reported was $47 \mathrm{I} \mu \mathrm{mol} / \mathrm{L}$ (standard deviation [SD] $76 \mu \mathrm{mol} / \mathrm{L}$, range $156-84 \mathrm{I} \mu \mathrm{mol} / \mathrm{L}$ ). The baseline demographic characteristics of the study group are presented in Table I. The mean maternal age was 29.8 (SD 4.3) years, and 9I women $(35.3 \%)$ were pregnant with their first child. The most common maternal ethnicity reported was white (55.4\%) followed by Asian (24.3\%), Aboriginal (7.6\%), black (5.2\%), Middle Eastern (4.0\%), Latin American (2.8\%) and other (I.0\%).

A cause for severe hyperbilirubinemia was identified in 93 cases $(36.0 \%$ ) (Table 2 ). ABO blood group incompatibility ( $n$ $=48$ ) was the most common cause, followed by G6PD deficiency $(n=20)$. Of those with $\mathrm{ABO}$ incompatibility, 32 cases $(66.7 \%)$ involved infants born to mothers with type O blood. In 165 cases $(64.0 \%)$ no cause was identified for the hyperbilirubinemia. The demographic characteristics did not differ significantly between cases with and without a specific diagnosis, although those with no specific diagnosis presented later than infants with an identified cause for the hyperbilirubinemia (4.9 [SD 3.0] v. 4.2 [SD 2.3] days of age; $p=0.05$ ).

Severe neonatal hyperbilirubinemia was identified in 73 infants before they were discharged from hospital. The remaining 185 infants were readmitted with hyperbilirubinemia from home. The median age of readmission was 5 days (range I-I9 days) (Fig. I). One hundred and twenty-one infants $(65.4 \%)$ were readmitted within 5 days of age. Thirtynine infants (2I.I\%) had lost more than I0\% of their birth weight at the time of readmission. The predischarge and readmission cohorts had similar birth weights, gestational ages and sex distribution (Table 3), but the readmission cohort had a much higher peak total bilirubin level $(p<0.00 \mathrm{I})$ and presented later $(p<0.00 \mathrm{I})$ (Table 3$)$. No difference was observed between the predischarge and readmission cohorts

Table 2: Causes of severe neonatal hyperbilirubinemia

No. of infants $n=93$

\begin{tabular}{lc} 
Cause & $n=93$ \\
\hline ABO incompatibility & 48 \\
G6PD deficiency & 20 \\
Other antibody incompatibility & 12 \\
Hereditary spherocytosis & 7 \\
Urinary tract infection & 2 \\
Sepsis & 1 \\
Pyruvate kinase deficiency & 1 \\
Hypothyroidism & 1 \\
Unstable hemoglobin & 1 \\
\hline
\end{tabular}


in the number of infants with a specific diagnosis (Table 3 ).

All but I infant received phototherapy. Fifty-seven infants (22.1\%) underwent an exchange transfusion. Other treatments included administration of albumin $(n=4)$, intravenous immunoglobulin $(n=3)$ and phenobarbital $(n=\mathrm{I})$. At the time of presentation, $5 \mathrm{I}$ infants ( $\mathrm{I} 9.8 \%$ ) had abnormal neurologic symptoms, including seizures, irritability, poor suck reflex and abnormal muscle tone. Thirteen infants had clinically important neurologic abnormalities at final discharge, including hearing loss $(n=10)$, seizures $(n=2)$, motor deficits $(n=2)$ and vision loss $(n=\mathrm{I})$.

\section{Interpretation}

Through this study we systematically estimated the number of infants with severe hyperbilirubinemia in Canada and the underlying causes. An estimate of the incidence of severe hyperbilirubinemia in Canada (assuming about 320 ooo live births per year) would be $\mathrm{I}$ in 2480 live births ( 258 in 640000 over the 2-year study period). ${ }^{21}$ It is anticipated that any infant in Canada with a total bilirubin level of more than $425 \mu \mathrm{mol} / \mathrm{L}$ would be referred to a pediatrician or neonatologist. Therefore, using the Canadian birth cohort as a denominator to estimate incidence would be appropriate. Despite a high response rate (the CPSP survey response rates in 2002, 2003 and 2004 were $83 \%, 83 \%$ and $82 \%)^{22}$ and strict case definitions, the estimate of $\mathrm{I}$ in 2480 live births is likely conservative given that this is based on voluntary reporting.

Since the shortened length of hospital stay for newborns was introduced in the early I9gos, neonatal readmission to hospital has increased. In both Canada and the United States the most common cause for infant readmission is severe hyperbilirubinemia. ${ }^{2,4,5}$ Our results raise concerns that underrecognition and inadequate investigation of severe hyperbilirubinemia in otherwise healthy infants contribute to early readmission and possibly long-term consequences, including bilirubin-induced encephalopathy and kernicterus. Our findings are consistent with the concerns previously raised by the

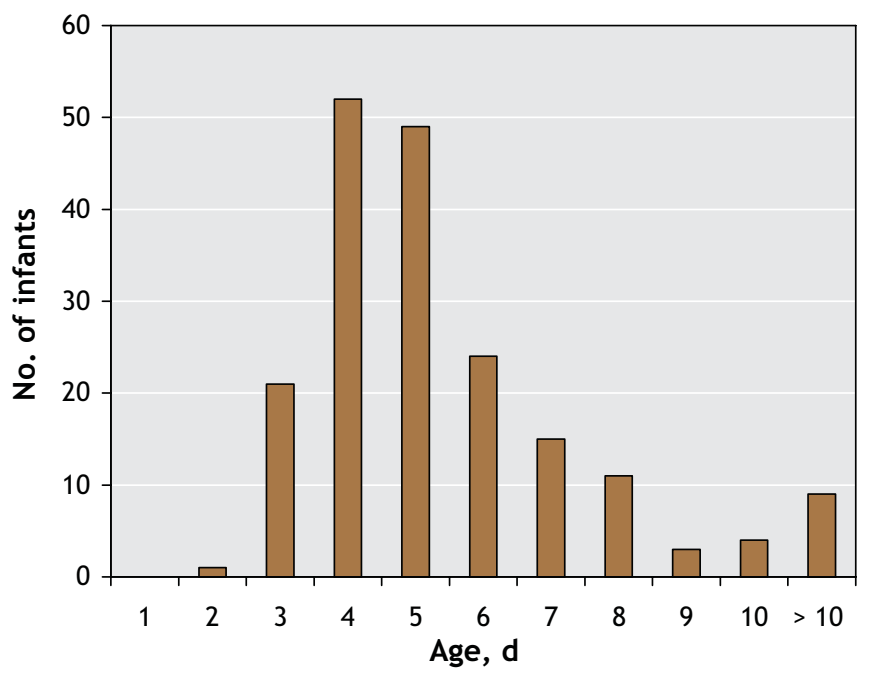

Fig 1: Age of readmission for discharged infants.
American Academy of Pediatrics and the US Centers for Disease Control and Prevention. ${ }^{11,12}$

It is often difficult for family practitioners or other primary care providers to evaluate all newborn infants within $48-72$ hours of discharge, as is recommended by the American Academy of Pediatrics. ${ }^{12,23}$ Similarly, the Canadian Paediatric Society recommends follow-up for newborns within 48 hours of discharge from hospital.20,24 Both associations recommend clinical assessment of infants for hyperbilirubinemia at these visits. However, it has been shown that visual inspection of newborns is not an accurate means of assessing the presence or severity of hyperbilirubinemia. ${ }^{25,26}$ Currently, cord blood tests for blood group type and Coombs tests are not routinely done in Rh-positive mothers. There is also no current recommendation regarding serum bilirubin testing for newborns other than a general sense that it should be readily available in the follow-up period. ${ }^{12,20,23}$ Bhutani and colleagues have demonstrated that measuring the serum bilirubin level before infants are discharged from hospital is helpful in predicting which infants will experience severe hyperbilirubinemia. ${ }^{\text {If }}$ a bilirubin test was done at the time of discharge, both followup planning and further testing (blood group, Coombs and G6PD tests) could be carried out to evaluate the risk of and to prevent severe hyperbilirubinemia.

Suresh and colleagues have suggested that it is not cost-ef-

Table 3: Characteristics of infants with severe hyperbilirubinemia identified before and after initial discharge from hospital

\begin{tabular}{|c|c|c|c|}
\hline Characteristic & $\begin{array}{c}\text { Identified } \\
\text { before discharge } \\
\quad n=73\end{array}$ & $\begin{array}{c}\text { Identified } \\
\text { after discharge } \\
n=185\end{array}$ & $p$ value \\
\hline $\begin{array}{l}\text { Gestational age, } \\
\text { wk, mean (SD) }\end{array}$ & $38.6(1.4)$ & $38.4(1.3)$ & 0.26 \\
\hline $\begin{array}{l}\text { Birth weight, g, } \\
\text { mean (SD) }\end{array}$ & $3369(495)$ & $3373(488)$ & 0.95 \\
\hline Sex, male, no. (\%) & $46(63.0)$ & $116(62.7)$ & 0.96 \\
\hline $\begin{array}{l}\text { Peak total bilirubin } \\
\text { level, } \mu \mathrm{mol} / \mathrm{L} \text {, mean } \\
\text { (SD) }\end{array}$ & $428(77)$ & $488(68)$ & $<0.001$ \\
\hline $\begin{array}{l}\text { Age at presentation, } \\
\text { d, mean (SD) }\end{array}$ & $2.6(2.2)$ & $5.4(2.6)$ & $<0.001$ \\
\hline $\begin{array}{l}\text { No. with diagnosis, } \\
\text { no. }(\%)\end{array}$ & $30(41.1)$ & $63(34.0)$ & 0.29 \\
\hline $\begin{array}{l}\text { Ethnicity, white, } \\
\text { no. (\%) }\end{array}$ & $40(54.8)$ & $90(48.6)$ & 0.25 \\
\hline $\begin{array}{l}\text { ABO } \\
\text { incompatibility, } \\
\text { no. (\%) }\end{array}$ & $15(20.5)$ & $34(18.4)$ & 0.69 \\
\hline $\begin{array}{l}\text { G6PD deficiency, } \\
\text { no. (\%) }\end{array}$ & $7 \quad(9.6)$ & $13(7.0)$ & 0.49 \\
\hline $\begin{array}{l}\text { Other antibody } \\
\text { incompatibility, } \\
\text { no. (\%) }\end{array}$ & $6 \quad(8.2)$ & $6 \quad(3.2)$ & 0.10 \\
\hline $\begin{array}{l}\text { Other diagnosis, } \\
\text { no. (\%) }\end{array}$ & 3 (4.1) & $10 \quad(5.4)$ & 0.67 \\
\hline
\end{tabular}

Note: G6PD = glucose-6-phosphate dehydrogenase. 
fective to obtain a serum bilirubin level from all infants when they are being discharged. ${ }^{27}$ However, the incidence of kernicterus and other permanent neurologic consequences associated with hyperbilirubinemia (e.g., sensorineural hearing loss) are not known. Cases of kernicterus continue to be reported worldwide..$^{4,10,28}$ Although our study was not designed to assess the incidence of long-term neurologic disease (e.g., kernicterus), a further systematic study estimating the incidence of kernicterus in Canada and its associated morbidity would be valuable.

A major limitation of the study was the reliance on self-reported data. Voluntary reporting invariably leads to underreporting, and therefore the true incidence of severe neonatal hyperbilirubinemia in Canada (and its associated causes) was probably underestimated. It was not possible to corroborate data reported by individual physicians, to clarify incomplete data or to follow-up inconsistent data entries. Despite the attempts to contact physicians who returned incomplete questionnaires by mail, email and phone, the study team was unable to obtain full information on all reported cases.

The results of this study demonstrate that severe neonatal hyperbilirubinemia continues to be a problem in Canada. Most infants were readmitted soon after discharge from hospital. Every effort should be made to identify at-risk newborns before they are discharged. This assessment should include measurement of serum bilirubin levels in infants who appear jaundiced or who have risk factors before they are discharged, preferably in the first few days of life. Laboratory testing to identity the cause needs to be complete in infants with clinically important hyperbilirubinemia. We recommend screening of infants born to mothers with type O blood, for blood type and Coombs' testing. Appropriate follow-up needs to be arranged before the infants are discharged, including repeat serum bilirubin testing if necessary. 8,9 Repeat serum bilirubin testing should be based on predictive hour-specific serum bilirubin normograms used when the infants are discharged. ${ }^{8,9}$

\section{This article has been peer reviewed.}

From the Department of Paediatrics, St. Michael's Hospital (Sgro, Campbell), and Mount Sinai Hospital (Shah), University of Toronto, Toronto, Ont.

Competing interests: None declared.

Contributors: Michael Sgro and Vibhuti Shah contributed to the study concept and design. All of the authors contributed to the acquisition, analysis and interpretation of the data and to the drafting and revision of the article. All of the authors gave final approval of the version to be published.

Acknowledgements: We thank Danielle Grenier for her ongoing advice and support during the project, Kinsley Jin for data collection and Kathleen Hollamby for administrative assistance.

We thank the Physician Services Incorporation for funding this study and the Canadian Paediatric Surveillance Program for the infrastructure and administrative support in developing this project.

\section{REFERENCES}

I. Tan-Dy C, Moore A, Satodia P, et al. Predicting kernicterus in severe unconjugated hyperbilirubinemia. Paediatr Child Health 2004;9(Suppl A):17A.

2. Lee $\mathrm{K}$, Perlman $\mathrm{M}$. The impact of early obstetric discharge on newborn health care. Curr Opin Pediatr 1996;8:96-ror.

3. Lee K, Perlman M, Ballantyne M, et al. Association between duration of neonatal hospital stay and readmission rate. J Pediatr 1995;127:758-66.

4. Liu S, Wen SW, McMillan D, et al. Increased neonatal readmission rate associated with decreased length of hospital stay at birth in Canada. Can J Public Health 2000;91:46-50.

5. Brown AK, Damusk K, Kim MH, et al. Factors relating to readmission of term and near-term neonates in the first two weeks of life. J Perinat Med I999;27:263-75

6. Bhutani VK, Johnson LH. Urgent clinical need for accurate and precise bilirubin measurements in the United States to prevent kernicterus. Clin Chem 2004;50: 477-80.

7. Bhutani VK, Johnson LH, Keren R. Diagnosis and management of hyperbilirubinemia in the term neonate: for a safer first week. Pediatr Clin North Am 2004;51:843-6r.

8. Bhutani VK, Johnson L, Sivieri EM. Predictive ability of a predischarge hour-specific serum bilirubin for subsequent significant hyperbilirubinemia in healthy term and near-term newborns. Pediatrics I999;103:6-I4.

9. Johnson LH, Bhutani VK. System-based approach to management of neonatal jaundice and prevention of kernicterus. J Pediatr 2002;140:396-403.

Io. Alotaibi SF, Blaser S, MacGregor DL. Neurological complications of kernicterus. Can J Neurol Sci 2005;32:311-5.

II. UMDNJ-Robert Wood Johnson Medical School Kernicterus Research and Prevention Center. Kernicterus: research activities. Available: www.cdc.gov/ncbddd/dd /kernres.htm (accessed 2006 Jul I8).

I2. American Academy of Pediatrics Subcommittee on Hyperbilirubinemia. Management of hyperbilirubinemia in the newborn infant 35 or more weeks of gestation. Pediatrics 2004;II4:297-316.

I3. Maisels MJ, Newman TB. Kernicterus in otherwise healthy, breast-fed term newborns. Pediatrics 1995;96:730-3

I4. Penn AA, Enzmann DR, Hahn JS, et al. Kernicterus in a full term infant. Pediatrics I994;93:1003-6.

I5. Harris MC, Bernbaum JC, Polin JR, et al. Developmental follow-up of breastfed term and near-term infants with marked hyperbilirubinemia. Pediatrics 200I;I07: I075-80.

I6. Newman TB, Maisels MJ. Less aggressive treatment of neonatal jaundice and reports of kernicterus: lessons about practice guidelines. Pediatrics 2000;105:242-5.

I7. Dennery PA, Seidman DS, Stevenson DK. Neonatal hyperbilirunbinemia. $N$ Engl Med 200I;344:58I-90.

I8. Joseph R, Ho LY, Gomez JM, et al. Mass newborn screening for glucose-6-phosphate dehydrogenase deficiency in Singapore. Southeast Asian J Trop Med Public Health I999;30(Suppl 2):70-I.

I9. MacDonald MG. Hidden risks: early discharge and bilirubin toxicity due to glucose-6-phosphate dehydrogenase deficiency. Pediatrics 1995;96:734-8.

20. Fetus and Newborn Committee, Canadian Paediatric Society (CPS). Approach to the management of hyperbilirubinemia in term newborn infants. Paed \& Child HIth I999;4:I6I-4.

2I. Statistics Canada. Births and birth rate, by province and territory. Available: www40.statcan.ca/lor/cstor/demoo4a.htm (accessed $2006 \mathrm{Jul}$ I8).

22. Canadian Paediatric Society. Canadian Paediatric Surveillance Program 2002 2004. Available: www.cps.ca/english/CPSP (accessed 2006 Jul I8).

23. American Academy of Pediatrics. Provisional committee for quality improvement and subcommittee on hyperbilirubinemia. Practice parameter: management of hyperbilirubinemia in the healthy term newborn. Pediatrics 1994;94:558-65.

24. Fetus and Newborn Committee, Canadian Paediatric Society (CPS). Facilitating discharge home following a normal term birth. Paed \& Child Hlth 1996;1:165-8.

25. Brown AK. Electronic monitoring of jaundice: better and quicker than the eye [abstract]. Ped Res I982;16:28IA.

26. Johnson LH, Bhutani VK. Guidelines for management of the jaundiced term and near term infant. Clin Perinatol I998;25:555-74.

27. Suresh GK, Clark RE. Cost-effectiveness of strategies that are intended to prevent kernicterus in newborn infants. Pediatrics 2004;II4:917-24.

28. Ebbesen F. Recurrence of kernicterus in term and near-term infants in Denmark. Acta Paediatr 2000;89:1213-7.

Correspondence to: Dr. Michael Sgro, Department of Paediatrics, St. Michael's Hospital, 30 Bond St., I5th floor Cardinal Carter, Rm. oI4, Toronto ON M5B IW8; fax 416 864-5344;

sgrom@smh.toronto.on.ca 